ENSAYO

\title{
DON QUIJOTE, AUTOR DE CERVANTES
}

\begin{abstract}
Alberto Manguel
Alberto Manguel, autor de una Historia de la lectura, se refiere en este artículo al auto-referimiento o juego de espejos en el Quijote de Cervantes. Ficción y realidad, desde un punto de vista narrativo, son intercambiables, y la verdad de la realidad como la verdad de la ficción dependen de nuestra voluntad como lectores. Nunca leemos un arquetípico original, sino una traducción de ese original vertido al idioma de nuestra experiencia, voz y lugar en el mundo. Milagro que Borges nos aclarara en 1939, en un texto ya clásico: "Pierre Menard, autor del Quijote".
\end{abstract}

Alberto Manguel nació en Buenos Aires, Argentina, en 1948. Crítico literario, ensayista, colaborador habitual en importantes diarios y revistas de distintas ciudades del mundo, ha dirigido seminarios sobre literatura en universidades de Europa, Canadá y Estados Unidos. Su obra, editada en castellano por Alianza Editorial, comprende las antologías Las puertas del paraíso: Antología del relato erótico, y Aguas negras: Antología del relato fantástico. Ha publicado también Guía de lugares imaginarios, en colaboración con Gianni Guadalupi, al estilo de las guías de viaje del siglo XIX, y las novelas $L a$ Puerta de marfil y Noticias del extranjero. Entre sus ensayos se cuentan En el bosque del espejo, sobre las palabras y el mundo; Una historia de la lectura, acerca del papel del lector —coeditado por la Fundación Germán Sánchez Ruipérez y Alianza Editorial- y Leer imágenes, en el que indaga sobre otras formas de lectura. Ha sido distinguido con numerosos galardones como el de Caballero de la Orden de las Artes y las Letras (Francia, 1996), el McKitterick First Novel (Reino Unido, 1992) y el de la Asociación de Escritores Canadienses. Creador de seriales y adaptaciones para radio y televisión, y de la obra teatral The Kipling Play. Actualmente reside en Francia; ha vivido en Italia y Canadá y desde 1988 es ciudadano canadiense.

Estudios Públicos, 100 (primavera 2005). 


\section{E \\ ntre las muchas maravillas que nos depara El ingenioso hidalgo} Don Quijote de la Mancha, hay una, que si no más misteriosa que las otras, es, al menos para mí, más desconcertante. Todos (aún quienes no han leído el libro) saben quién es Don Quijote. A su lado, Cervantes es casi fantasmagórico, un personaje mucho menos importante de la obra, un intruso que de vez en cuando comenta y opina sobre la acción, un desocupado lector que un día halló un bulto de papeles en un mercado de Toledo y se lo hizo traducir para así dar a luz las aventuras del iluminado caballero. Cervantes, digo, es un personaje menor que cede con los años sus características físicas al héroe de la historia. A partir del siglo diecinueve, la transformación es definitiva, y los ilustradores del Quijote entienden que ambos son idénticos. El Don Quijote lampiño de los primeros grabados se esfuma y aparece en cambio un caballero que usurpa los rasgos cervantinos: su "rostro aguileño . . nariz corva . . barbas de plata . . dientes ni menudos ni crecidos, porque no tiene sino seis, y ésos mal acondicionados y peor puestos . . . el cuerpo entre dos extremos, ni grande ni pequeño . . . algo cargado de espaldas y no muy ligero de pies . ..” Esta descripción que Cervantes hace de sí mismo a los 66 años de edad, es la de Don Quixote frisando los 50: "seco, avellanado, antojadizo . . . de complexión recia, seco de carnes, enjuto de rostro". La creación artística cobra cuerpo y experiencia, mientras que su autor permanece inmutable en el tiempo, inalterable como un frontispicio.

Es posible que Cervantes sospechara tal destino. Cuando en el sexto capítulo de la primera parte, el cura y el barbero purgan la biblioteca de Don Quijote y encuentran, junto al Cancionero de López Maldonado, la inconclusa Galatea de Miguel de Cervantes, ocurre la primera instancia de este juego vertiginoso: Cervantes existe porque Don Quijote lo ha leído, y $L a$ Galatea se salva porque el cura dice ser, desde hace muchos años, gran amigo del autor. Y aquí el lector se encuentra ante un primer abismo: si las páginas que está recorriendo son ficción, entonces el autor de esas páginas pertenece a esa ficción; y aquel que las está leyendo (el lector partícipe en la historia) no reside ya en el mundo de cosas tangibles sino en un círculo de existencias imaginarias cuya permanencia depende sólo de un acto de fe - fe en la realidad de esa ficción.

Cervantes (o esa figura imaginaria que llamamos Cervantes) da varias vueltas de tuerca más a esta maquinaria ficticia. Cuando al cabo de apenas ocho capítulos, y en la mitad de una aventura, Cervantes confiesa no saber proseguir con la historia de su caballero, ocurre un milagro. Hallándose un día en el Alcaná de Toledo, dice Cervantes, encuentra un cartapa- 
cio lleno de papeles escritos en caracteres arábigos $\mathrm{y}$, puesto que no sabe leerlos, busca un morisco aljaimado (es decir, un moro que habla castellano) para que se lo traduzca. Descubre entonces que el manuscrito es de un tal Cide Hamete Benengeli, y que narra la continuación de la historia de Don Quijote. Es decir: dependiendo de nuestro punto de partida, Cide Hamete Benengeli escribe la historia de Don Quijote que un morisco de Toledo traduce para Cervantes, ese Cervantes que es un personaje en los capítulos que la preceden; o, el personaje Cervantes, autor de un libro que se encuentra en casa de Don Quijote, se hace contar la historia de lo que sigue a las primeras aventuras del caballero, por un traductor que puede leer el manuscrito de un autor árabe que escribe en aljaimía, es decir, un texto morisco en lengua romance, transcrito en caracteres árabes. El libro que lee el lector de Don Quijote es uno que, por donde se lo abra, englute la realidad y la vuelve ficción, para hacerla más real. "Las historias fingidas tanto tienen de buenas y de deleitables cuanto se llegan a la verdad o la semejanza della, y las verdaderas tanto son mejores cuanto son más verdaderas," dice Don Quijote al descubrir el apócrifo Quijote de Avellaneda en una imprenta de Barcelona, en el capítulo 62 de la segunda parte. Cervantes (y Don Quijote) reconocen esta regla esencial de la literatura: hay grados de verdad a los cuales sólo podemos llegar a través de la ficción.

Hasta tal punto asume la ficción de Cervantes la realidad para hacerla "más verdadera", que acaba por canibalizarse a sí misma. En el segundo capítulo de la segunda parte, el bachiller Carrasco hace saber a Sancho que sus aventuras están contadas en un libro (que Carrasco ha leído en Salamanca, universidad seria si las hay) "con nombre del Ingenioso Hidalgo don Quijote de la Mancha". Al oír esto, Sancho se hace cruces espantado: reacción similar debe tener el lector para quien, si la primera parte del libro que tiene entre las manos ha sido leído por los personajes de la parte que está leyendo ahora, él, lector de carne y hueso, es también parte de ese acuerdo, de esa treta, de ese mundo imaginario, fantasma entre los fantasmas, dependiente no de sus propias acciones sino de los sueños de otro que ahora es polvo y cenizas y que alguna vez se llamó Miguel de Cervantes Saavedra.

Este método de auto-referimiento o juego de espejos (que Gide, inspirándose en un término de la heráldica, llamó "mise-en-abyme"), es antiquísimo.

En la corte de Alcino, en el octavo libro de la Odisea, un huésped extranjero, a quien el rey ha acogido, oye al poeta Demódoco (ciego como 
dicen que era Homero) cantar la lucha entre Ulises y Aquiles en Troya; nadie sabe que el huésped es Ulises quien, al escuchar cantar sus propias hazañas, oculta su cara bajo su capucha para que no lo vean llorar. Homero ofrece a Demódoco (su Cide Hamete) la autoría de la Ilíada como Cervantes otorgó a Cide Hamete la de la primera parte del Quijote y hace que Ulises (como Don Quijote en la segunda parte) la escuche narrar, emocionado.

Chaucer, en los Cuentos de Canterbury, se incluye a sí mismo entre sus peregrinos y se hace contar una de las narraciones. Pero la cuenta tan mal y de forma tan torpe, que sus compañeros de viaje le piden que la interrumpa. La ficción de Chaucer contiene a Chaucer, pero un Chaucer inepto, tal como la biblioteca de Don Quijote incluye a Cervantes, pero un Cervantes inconcluso, salvado por el cura sólo por su amistad, no por su genio literario.

Borges, en un pequeño ensayo sobre las magias parciales del Quijote, publicado en La Nación de Buenos Aires en 1949, propuso otras: el caso de Hamlet, que hace representar a los actores en la corte de Elsinore una obra titulada La ratonera que es, más o menos, la tragedia de Hamlet; y el Ramayana, el poema de Valmiki escrito en sánscrito hacia el cuarto siglo a.C., en cuyo último libro un extraño asceta enseña a leer a los hijos de Rama: el asceta es Valmiki, el libro en el que estudian, el Ramayana.

Dicho de otro modo: ficción y realidad son, desde un punto de vista narrativo, intercambiables, y la verdad de la realidad como la verdad de la ficción dependen de nuestra voluntad como lectores. El texto fija una verdad narrativa; el lector impone otra o la misma que desdobla, extiende, refleja y transforma la de la página escrita. Borges, en un texto hoy clásico, nos aclara el milagro.

Un cierto día de septiembre de 1939 en Buenos Aires (Byrd estaba por comenzar su tercera expedición antártica y las primeras cartas "vía aérea" desde Inglaterra acababan de llegar a las costas porteñas) los pocos lectores suscriptos a la revista Sur leyeron un breve texto firmado "Jorge Luis Borges" en el que se alababa con fervor crítico la obra de un tal Pierre Menard. Algunos amigos felicitaron a Borges con más lealtad que entusiasmo; un viejo colega, con ejemplar pedantería, le dijo que sus comentarios sobre Menard, si bien justos, no decían nada sobre Menard que no se hubiese dicho antes. Ni los distraídos lectores de Sur, ni los atentos amigos del autor, ni la directora de la revista, la perspicaz Victoria Ocampo, tal vez ni siquiera el propio Borges, se dieron cuenta que aquella publicación marcaba una de las pocas fechas esenciales de la historia de la literatura. Tal inaten- 
ción no hubiera sorprendido a Borges quien trece años más tarde, en un artículo llamado "El pudor de la historia" declararía: "Yo he sospechado que la historia, la verdadera historia, es más pudorosa y que sus fechas esenciales pueden ser, asimismo, durante largo tiempo, secretas".

"Pierre Menard, autor del Quijote" nació con voluntad de fracaso. Los hechos que lo engendraron son harto conocidos. Durante la Navidad de 1938, Borges se hirió la frente con el borde de una ventana abierta. La herida se infectó y durante varias semanas los médicos creyeron que moriría de septicemia. Cuando empezó a reponerse, temió haber perdido sus capacidades mentales y dudó poder volver a escribir. Hasta aquel momento había publicado poemas y reseñas literarias. Pensó que si probaba escribir una reseña y no lo lograba, se sentiría incapacitado para siempre. Pero si trataba de hacer algo nuevo, algo que no había intentado antes, y fallaba, no juzgaría el fracaso tan grave y quizás el hecho mismo lo prepararía para la severa revelación final. Decidió escribir un cuento. El resultado fue "Pierre Menard...”.

Pierre Menard es el lector ideal, el hombre que quiere rescatar un texto volviéndolo a crear tal como su autor lo concibió. Borges explica: "No quería componer otro Quijote - lo cual es fácil- sino el Quijote. Inútil agregar que no encaró nunca una transcripción mecánica del original; no se proponía copiarlo. Su admirable ambición era producir unas páginas que coincidieran — palabra por palabra y línea por línea — con las de Miguel de Cervantes". Que en última instancia la tarea sea imposible, que el texto reimaginado sea ahora (a pesar de la coincidencia formal entre los dos) de Menard y ya no de Cervantes, es la lección implacable que aguarda a cada lector. Nunca leemos un arquetípico original: leemos una traducción de ese original vertido al idioma de nuestra propia experiencia, de nuestra voz, de nuestro momento histórico y de nuestro lugar en el mundo, como los lectores de Cervantes leyeron no una crónica de Cide Hamete Benengeli, sino un texto traducido al vocabulario castellano de inicios del siglo diecisiete.

La terrible conclusión de Pierre Menard es ésta: El ingenioso hidalgo Don Quijote de la Mancha de Miguel de Cervantes Saavedra no existe, y nada podrán contra este hecho irrefutable la amenaza de celebraciones, institutos cervantinos, cursos de literatura española, sesudos estudios críticos y ediciones de obsceno lujo. El Quijote original, si insistimos en creer en su existencia, desapareció con el lector Cervantes. Sólo quedaron (lo cual no es poco) los cientos de millones de Quijotes leídos desde que un primer Quijote entró en la imprenta de Juan de la Cuesta y salió despojado 
de una parte de los capítulos XXIII y XXX. Desde entonces, los colegas de Pierre Menard han invadido el mundo de las letras y nos han dado (y siguen dándonos) sus múltiples Quijotes: el torpe Quijote de Lope, el divino Quijote de Dostoievski, el filosófico Quijote de Unamuno, el brutal Quijote de Nabokov, el risueño Quijote de Graham Greene, el tedioso Quijote de Martin Amis, el desdoblado Quijote de Borges, el Quijote de cada uno de nosotros, sus desocupados lectores.

Borges observaría, en un ensayo fundamental sobre Kafka, que "cada escritor crea a sus precursores". Menard no es distinto y a partir de su propia existencia creó una vasta genealogía que incluye, entre muchos otros, al Diderot de "Esto no es un cuento", al Lawrence Sterne de Tristam Shandy, al Italo Calvino de Si una noche de invierno un viajero... También, a Robinson Crusoe que lee la Biblia como si fuese una crónica de sus propias desventuras, a Hamlet que lee "palabras, palabras, palabras" y ve en una nube un camello, una comadreja o una ballena, a un tal William Sefton Moorhouse que se convirtió a la fe cristiana leyendo la Anatomía de la melancolía de Burton creyendo que se trataba de un manual teológico de Butler, a los censores militares que prohibieron la entrada a la Argentina de El rojo y el negro, pensando que trataba de una apología del comunismo. Acaso no había sugerido Borges, a propósito de Pierre Menard, que "atribuir a Louis Ferdinand Céline o a James Joyce la Imitación de Cristo ¿no es una suficiente renovación de esos tenues avisos espirituales?”.

En América Latina, tenemos una tradición de lecturas creativas (por así llamarlas) que comienza con la invasión española. Colón famosamente no quiere llegar a América (que no sabe existe) sino a las Indias, y ve en la extraña tierra un irrefutable muestrario de sus expectativas, nacidas en el mundo mitológico de Grecia y Roma, y en el mundo caballeresco de Arturo y de Tirant lo Blanc. Los seres fabulosos de la antigüedad y de las novelas de caballería prestaron realidad a las maravillas del Nuevo Mundo; las recompensas prometidas a los héroes de la literatura (como el vellocino de oro a Jasón y Elena al príncipe Paris), justificaron en la imaginación europea las rapiñas y los saqueos de los reinos indígenas. El Nuevo Mundo es, desde el principio de la invasión, un mundo imaginario, no como aquel de polvo y piedra que atraviesa Sancho sino aquel de reinos mágicos por el que se aventura Don Quijote, poblado no de comerciantes y arrieros y otros seres ordinarios, sino de princesas y hechiceros y gigantes y paladines.

El historiador Irving Leonard (Books of the Brave) cuenta como, por ejemplo, en la novela de Sergas de Esplandián (publicada años antes de la 
entrada de Cortés en Méjico), el caballero no tiene escrúpulos de matar al león que protege la entrada a un antiguo sepulcro ni de apoderarse del fabuloso tesoro que allí se encuentra, porque su misión es heroica, y un héroe tiene todos los derechos. Así lo creyeron los conquistadores europeos que no tuvieron escrúpulos de allanar tumbas y profanar templos para apoderarse de los tesoros de los incas y aztecas. Para ellos, América era prueba de la verdad de la ficción: una tierra imaginaria que, gracias a sus intrépidos viajes, ahora cobraba por fin realidad física. Cuando Cristóbal Colón, durante su viaje de regreso a España en enero de 1493, cuenta que vio tres sirenas "que salieron bien alto de la mar," no se le ocurre pensar que está viendo tres animales nuevos - tres manatíes en este caso, esa especie de lobo marino del Caribe - sino que, al contrario, insiste en corregir las antiguas autoridades literarias y anota: "pero no son tan hermosas como las pintan".

Leer el Quijote hoy es una tarea casi imposible. Quiero decir, no puede leerse el Quijote como un libro virgen, cuyas páginas nunca hemos abierto. Vivimos en un mundo que es, en gran parte, fruto de la lectura del Quijote. Generaciones de interpretaciones y comentarios previos, las alabanzas oficiales obligatorias en casi todo acto literario, las historias de la literatura española y también universal, los ecos quijotescos en cientos de obras célebres, las multitudes de ilustraciones y retratos de nuestros héroes, y hasta las chucherías turísticas con las que los viajeros tratan de inmortalizar su visita a España, brindan al más ingenuo de los lectores un ampuloso preámbulo que cuenta y juzga a priori la obra, hasta para aquellos que no tendrán nunca al libro en sus manos. Hoy no hay lectores del Quijote: sólo relectores. En el ya citado capítulo 62 de la segunda parte, los amigos del anfitrión de Don Quijote le cosen a la espalda del caballero un pergamino en el que se lee: "Éste es Don Quijote de la Mancha", de modo que, cuando se pasea por Barcelona, todos saben quién es y lo llaman por su nombre. Así le ha ocurrido a Don Quijote en el mundo que llamamos real. "Éste es Don Quijote de la Mancha" reza el pergamino en todas las lenguas del mundo. Y todos repetimos, la mayoría sin leer más que el cartel, "Sí, éste es Don Quijote, autor de Miguel de Cervantes".

A partir de Pierre Menard, nadie puede volver a leer un libro, cualquier libro, de la misma manera que pensaban leerlo nuestros antepasados. Menard nos ha vuelto creadores o, más bien, nos ha obligado a ser conscientes, como lectores, de nuestra responsabilidad creativa - responsabilidad detallada por muchos pero reconocida por casi ninguno. Antes de 
aquel mes de septiembre de 1939, podíamos creer que un libro insulso o maravilloso o altisonante o transformador debía su calidad exclusivamente al ingenio de su autor. Después de aquella fecha, no sin cierto orgullo y no sin cierto terror, sabemos que no es así.

14 de septiembre 2005 . 